services, embryonic in places, is further threatened by the premature closure of psychiatric hospitals in some areas before tailor-made Regional Secure Units have been developed. Similar problems, but in respect of community resettlement, are affecting the learning disability psychiatric services. Psychiatric services for the elderly are particularly affected by the lack of community provision and insufficient social work input. Specific substance misuse services are especially affected by the severity and extent of the problem in London, its relationship to homelessness and, again, the absence of facilities for social rehabilitation and aftercare. Finally, Academic
Departments of Psychiatry, within London in particular, have sometimes developed highly specialised services, often bed-based. Such services sometimes demonstrably effective and essential to research, are under special threat because of their idiosyncratic development and perceived irrelevance to local need.

Overall, the establishment of a pan health care system for London, not broken down by Regions, was thought to be worthy of serious consideration.

It is rumoured that Sir Bernard will be reporting to the Secretary of State in October 1992.

Professor A. H. CRISP Chairman of the Working Party

\title{
Revised guidelines for collaboration between physicians in geriatric medicine and psychiatrists of old age
}

Since 1979, consultants in psychiatry of old age and geriatric medicine have used the excellent guidelines drawn up by Professor T. Arie and agreed by the Standing Joint Committee of the British Geriatrics Society and the Royal College of Psychiatrists to determine which patients each group should be responsible for. Then, as now, there were concerns that some patients might fall between two stools.

The NHS reorganisaton and the enactment of new community care legislation have made it essential that psychiatrists and physicians have a close and effective working relationship. The emphasis on purchaser/providers and the need to assess all patients in order to plan individual packages of care make it crucial that the expertise in geriatric medicine and psychiatry of old age be utilised. The two specialties need to work closely together to ensure that assessments and necessary care be carried out efficiently, without overlap or undue delay.

The two specialties need to agree principles of collaboration which are most likely to improve quality of clinical care, as opposed to mere expediency. Such guidelines should be widely publicised among the medical profession, management and the general public.

The following principles should apply.

1. Specialist health services for the elderly should be a unity for "consumers" (i.e. patients, carers, referrers). Transfers should be smooth and mutually agreed by the professionals, even when an initial referral was inappropriate, to ensure the most appropriate management of individual patients.

2. Unity does not mean blurring of the specificity of the particular professions and facilities within the service or the patients' right of access to them.

3. Assessment by physicians in geriatric medicine and psychiatrists in the care of the elderly must be included as an essential component of services in directly managed and selfgoverning "trust" hospitals. Liaison between the two specialties should be included in "job plans", "service agreements" and "business plans".

4. Adequate resources in the whole range of geriatric medicine, the psychiatry of old age and social services provision are required to draw up community care plans and for the best management of individual elderly patients. There should be sufficient health provision for long term care. Inadequate resources inhibit collaboration.

5. Clear criteria for division of responsibility must be known and accepted both inside and outside the specialties, and should not be influenced by lack of resources; $a$ psychiatric patient does not become geriatric simply because there are no psychiatric beds or vice versa.

6. Effective collaboration depends on mutual confidence and trust. Collaboration should involve not only physicians and psychiatrists, but also other members of the "multidisciplinary team".

7. Mutual confidence requires understanding of each other's disciplines. Some reciprocal training in each other's specialty should be mandatory for accreditation for higher professional training. The presence of a physician 
in geriatric medicine as an additional member on the appointment panel for a psychiatrist of old age, and vice-versa, is desirable.

8. Responsibility should be determined by the assessed clinical and care needs of the patient, not by quirks of referral or exigencies of resource constraints (e.g. bed shortages).

9. Some patients fall into a "grey area" where they might appropriately be dealt with by either service. This then becomes a matter for negotiation between the two services, but the service which first made contact retains ultimate responsibility until placement is agreed. No patient should be allowed to "fall between two stools".

10. Both physicians and psychiatrists should be able to make diagnoses of delirium and dementia, assess their severity and carry out appropriate investigations. Where the treatment of delirium requires more than the minimum of medical management the physician should be responsible. When patients with dementia have major behavioural problems, the psychiatrist should be responsible.

11. The presence or absence of major behavioural problems such as severe restlessness or disruptive aggression rather than mobility should be the principal criterion for psychiatric intervention and management after initial assessment, except in those few cases where the physical dependency is very severe. Mobile dementia sufferers without such problems primarily need appropriate social care and support.

12. The currently assessed clinical needs of patients at home rather than their past medical or psychiatric history should determine their referral and placement.

13. Speedy systems of cross-referral between physicians and psychiatrists should be established to expedite a patient's passage through the care management process. The speed of response depends on the clinical urgency.

14. Joint assessment depends more on the good will and co-operation of professional colleagues than on the presence of a specifically designated joint assessment unit. However, separate assessment units should be reasonably accessible, preferably both on the District General Hospital site.

15. These principles of collaboration also apply to physicians and psychiatrists who combine general medicine or psychiatry with a special interest in, or responsibility for, the elderly. The guidelines are as relevant to the management of patients referred from other hospital settings (e.g. orthopaedic wards), as they are to those in the community or already within geriatric or psychiatric facilities.

16. Representatives of consultants in both geriatric medicine and the psychiatry of old age should have continuing involvement in, and influence on, the joint planning of services by local health services and the social services.

Drafted by Drs P. S. Murdoch and E. A. Montgomery based on guidelines produced in 1979 (Professor T. Arie) and by the Standing Joint Committee of the British Geriatrics Society and the Royal College of Psychiatrists.

Approved by Council, 19 June 1992. 